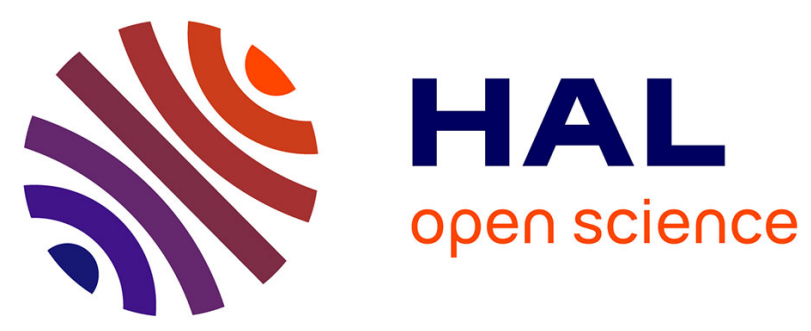

\title{
Quasi-in-situ sizing of nanoparticles by laser-induced incandescence during the floating chemical vapor deposition synthesis of carbon nanotubes
}

Yiguo Xu, Yang Ma, Delong He, Hanlu Zhang, Laurent Zimmer, Anthony

Dichiara, Paul Haghi-Ashtiani, Jinbo Bai

\section{To cite this version:}

Yiguo Xu, Yang Ma, Delong He, Hanlu Zhang, Laurent Zimmer, et al.. Quasi-in-situ sizing of nanoparticles by laser-induced incandescence during the floating chemical vapor deposition synthesis of carbon nanotubes. Applied Physics B - Laser and Optics, 2019, 125 (6), pp.93. 10.1007/s00340-019-7201-4 . hal-02152057

\section{HAL Id: hal-02152057 \\ https://hal.science/hal-02152057}

Submitted on 21 May 2020

HAL is a multi-disciplinary open access archive for the deposit and dissemination of scientific research documents, whether they are published or not. The documents may come from teaching and research institutions in France or abroad, or from public or private research centers.
L'archive ouverte pluridisciplinaire HAL, est destinée au dépôt et à la diffusion de documents scientifiques de niveau recherche, publiés ou non, émanant des établissements d'enseignement et de recherche français ou étrangers, des laboratoires publics ou privés. 


\title{
Quasi-in-situ sizing of nanoparticles by laser-induced incandescence during the floating chemical vapor deposition synthesis of carbon nanotubes
}

\author{
Yiguo $\mathrm{Xu}^{1, a}$. Yang $\mathbf{M a}^{2, a} \cdot$ Delong \\ He $^{1, *} \cdot$ Hanlu Zhang ${ }^{1} \cdot$ Laurent \\ Zimmer $^{3}$ - Anthony Dichiara ${ }^{4}$. Paul \\ Haghi-Ashtiani $^{1}$. Jinbo Bai ${ }^{1, *}$
}

Received: date / Accepted: date

\begin{abstract}
In this study, laser-induced incandescence (LII) diagnostic technique was applied for iron-based nanoparticle (NP) sizing during the floating chemical vapor deposition (CVD) synthesis of carbon nanotubes (CNTs). Transmission electron microscopy (TEM) was used to characterize the nature and size of NPs. The LII signal was simulated by taking into account the carbon-encapsulated iron NP density, heat capacity and size distribution, etc. A detailed sensitivity and uncertainty of the key parameters on the evaluated particle size for this model has also been estimated. Using the developed approach, the evolution of NPs in the gas phase along the reactor axis was investigated at 650,750 and $850{ }^{\circ} \mathrm{C}$. It is found that the evaluated size from LII signals is in good agreement with the one obtained by TEM measurements. The NP size is highly dependent on the temperature in the studied conditions but it does not show obvious difference along the reactor axis. This study reveals the important LII application prospect to understand the catalyst particle behaviors for better control over CNT growth during the floating CVD process in the future.
\end{abstract}

\section{Introduction}

Due to their extraordinary intrinsic properties, CNTs have made themselves very attractive and can be potentially used in various fields such as energy storage [1, 2], environmental remediation[3,4] and structural composites [5]. These exhibited

${ }^{a}$ Contributed equally to this work.

* Corresponding author: Jinbo Bai(jinbo.bai@ecp.fr), Delong He(delong.he@ecp.fr)

${ }^{1}$ Laboratoire MSSMat, CNRS UMR 8579, CentraleSupélec, Université Paris-Saclay, 8-10 rue Joliot-Curie, 91190, Gif-sur-Yvette, France

${ }^{2}$ Key Laboratory of Aerospace Advanced Materials and Performance of Ministry of Education, School of Materials Science and Engineering, Beihang University, 100191, Beijing, China

3 Laboratoire EM2C, CNRS UPR 288, CentraleSupélec, Université Paris-Saclay, 8-10 rue Joliot-Curie, 91190, Gif-sur-Yvette, France

4 School of Environmental and Forest Sciences (SEFS), University of Washington, 4000 15th Ave NE, Seattle, WA 98195, USA 
properties in mechanics, electrics and thermotics are strongly related to their morphology, length, diameter, wall numbers and crystallinity [6]. However, the ability to obtain CNTs with specific and uniform properties in large amount still remains a challenge and several post-treatment steps are usually demanded [7]. Among all the different synthesis methods, floating catalyst CVD (FCCVD) approach, where both carbon feedstock(s) and catalyst precursor(s) are simultaneously fed into the reactor, allows low cost, high quality and continuous production for industrial purposes $[8,9]$. Ferrocene is used as the catalyst precursor in this study due to its low cost and non-toxicity. Even if the CNT synthesis by FCCVD always occurs on a substrate like the quartz plate or the microspherical alumina particle, many researchers proposed that the catalytic NPs formation takes place in the gas phase by homogeneous nucleation [10-13], because the catalytic NPs originate from decomposition of ferrocene in the gas phase, as depicted in Figure 1a. CNT growth precedes through several processes, such as, the NP nucleation and the following diffusion, precipitation of decomposed carbon on the catalytic NPs. In practical all the processes may occur simultaneously at the same region in the reactor. It has been believed that the catalyst NP size and nature have a significant effect on the control of the CNT morphology, such as the CNT diameter [14] as well as their chirality $[15,16]$. Therefore, controlling the formation of iron-based catalyst NPs is highly desired for high quality CNT synthesis at a large scale. In order to achieve an in-depth understanding of the catalytic NP formation mechanism, it is reasonable to develop an in-situ diagnostic technique to trace the catalyst evolution and study the performance of these catalysts during the FCCVD process.

LII phenomenon occurs when a high-energy pulsed laser beam encounters particles like carbonaceous soot or metallic particles. When particles are heated up by a pulsed laser of $\sim 10 \mathrm{~ns}$ duration, their temperature increases to $\sim 4000 \mathrm{~K}$ immediately for laser intensities of $1 \times 10^{7} \mathrm{~W} / \mathrm{cm}^{2}$ or greater [17]. Meanwhile, the particles loose energy by heat transfer mechanisms such as conduction, radiation, evaporation, oxidation, among which thermal radiation leads to the LII emission. The research on LII was first outlined by Weeks and Duley in 1974 [18]. It was found that the aerosol particles generated form sub-micron powders of carbon black and alumina released a momentary emission of light when heated by TEA $\mathrm{CO}_{2}$ laser pulses. The spectrum of this emission related to the particle size. In 1977 Eckbreth found several interferences during the Raman scattering experiments, which were identified to be laser modulated particulate incandescence [19]. They also proposed an analytical model to describe this process. The real pioneer of LII technique is Melton. In 1984 Melton improved the equations governing the laser heating and vaporization of particles [20]. This work exploited the potentiality of LII as a powerful diagnostic tool for soot concentration measurement and particle sizing. A time-resolved variant of LII (TiRe-LII) was introduced to allow particle sizing by recording the time-dependent particle emissions during particle cooling after the laser heating by Roth [21,22] and Will [23]. In $2004 \mathrm{H}$. Bladh extended the theoretical model for TiRe-LII to include particle-size distributions and different spatial distributions of the laser energy [24]. In the past decades LII had undergone significant developments. Following the earlier modeling work of Weeks and Duley [18], different detailed models were developed to serve as means to extend LII technique to a wider variety of conditions, including high pressures and low temperatures [25-30]. In $2002 \mathrm{R}$. Vander Wal et al. first applied LII to study the CNT flame synthesis [31]. Snelling and coworkers developed the auto- 
compensating LII. LII technique can archive a quantitative measurement of volume fraction without further calibration process by using another soot measurement technique [32]. The early experiments about LII focus on soot size measurements $[20,23,33]$. Due to its non-intrusive, real-time and in-situ nature, it has recently been spread to a variety of a range of sources, such as $\mathrm{Cu}$ [34], Mo [35-37], Ag [22], $\mathrm{W}$ [38], Ti [39], and Fe [39-47], and Fe-C binary NPs [48,49]. LII has proven to be a powerful tool for particle concentration and primary particle size measurement and was used in a wide range of applications, such as combustion [50-52], particle synthesis [53,34] and environment [54-58]. However, LII technique has rarely been applied for catalytic NP sizing during CNT synthesis. The mechanistic investigation of carbon nanotube formation was examined by Cau et al. within the framework of laser vaporization by combining LII and laser-induced florescence (LIF) [59]. Recently Yatom et al. also conducted LII measurements in the carbon arc discharge for synthesis of CNTs [60]. However, the synthesis of carbon nanotube by laser vaporization and carbon arc discharge are different from CNT growth by floating catalyst CVD.

In this study, the LII technique is applied for the FCCVD synthesis of CNTs. The typical equipment used in FCCVD is a horizontal quartz tube heated by an electric furnace. However, In this situation, however, NPs are also being deposited on the inner wall of the reactor and may contribute to the LII signal and/or prevent the response of the floating NPs from being collected by the detector located outside the reactor. To avoid the effect of the deposited NPs on the LII signals, a stainless steel reactor with seven 15 -cm long stainless steel open-ended tubes (6.3 $\mathrm{mm}$ in diameter) welded perpendicular to the reactor axis was designed and the gas exhaust was probed by LII at the end of each 15 -cm long tubes. Then we conducted a validation experiment inside the reactor, where a copper grid with lacey carbon films was placed into the tube furnace. This comparative study revealed that there are no statistical differences in size and structure between the NPs inside the reactor and those collected at the location where the LII signal was probed. Furthermore, the results obtained by LII sizing were compared with TEM observation. The good agreement between the NP sizes estimated by both LII and TEM demonstrates the validity of this approach. Using this approach, the evolution of NPs in the gas phase along the reactor axis was investigated at different temperatures. These results contribute to analyze potential relations between the floating NPs and the CNTs on the substrate which were barely discussed caused by the lack of a proper method, revealing the great LII application prospect for the FCCVD CNT growth mechanism research.

\section{Experimental section}

The experimental setup depicted in Figure $1 \mathrm{~b}$ comprises a $120 \mathrm{~cm}$ long stainless steel reactor ( $45 \mathrm{~mm}$ in diameter) heated by a horizontal electrical furnace (Carbolite). The reactor was opened at seven positions using $15-\mathrm{cm}$ long stainless steel tubes $(6.3 \mathrm{~mm}$ in diameter) welded perpendicular to the reactor axis to provide optical access to the reactive atmosphere for LII analysis [61]. No obvious size and structure change of NPs were observed from inside of the reactor to the outlet of the small tubes. The CVD process was carried out at 650,750 and $850{ }^{\circ} \mathrm{C}$ under argon atmosphere in the presence of hydrogen. Acetylene was also introduced in 
the system to serve as carbon source $[62,63]$. Gas flows were adjusted using digital mass flow controllers (Bronkhorst) and the total flow rate was kept constant at 1 $\mathrm{L} / \min \left(0.78 \mathrm{~L} / \min \mathrm{Ar}, 0.20 \mathrm{~L} / \mathrm{min} \mathrm{H}_{2}, 0.02 \mathrm{~L} / \operatorname{min~} \mathrm{C}_{2} \mathrm{H}_{2}\right)$. During the CVD process, a solution of ortho-xylene (98.5\% Alfa Aesar) containing dissolved ferrocene $(0.05 \mathrm{~g} / \mathrm{mL})$ was injected in the form of a spray at a rate of $0.2 \mathrm{~mL} / \mathrm{min}$ using a syringe pump equipped with a liquid flow meter (Razel Science, R99-E) [64,65].

The gas exhaust was probed by LII at the end of each $15-\mathrm{cm}$ long stainless steel open-ended tubes, as shown in Figure 1. The LII signals were generated using a pulsed Nd:YAG laser (Excel, Surelite II-10), which delivered $1064 \mathrm{~nm}$ emissions with $7 \mathrm{~ns}$ pulse duration and $2 \mathrm{~Hz}$ repetition rate. The non-focalized laser beams had a diameter of $7 \mathrm{~mm}$ and the laser fluence was monitored using an energy meter (Gentec, UP19K-15S-VM-D0) at different Q-switch values. The laser beams were directed along the CVD reactor such that the excitation of the floating particles occurred at the outlet of each open-ended tubes. The incandescence signals were collected at different positions along the reactor using an optical fiber facing each one of the open-ended tubes. The detection was arranged perpendicular to the excitation axis to minimize Rayleigh scattering. A beam splitter divided the collected particle radiation into two beams, which were arranged perpendicular to each other. Narrow band-pass filters with center-wavelengths of $492 \pm 10$ and $694 \pm 10 \mathrm{~nm}$ were placed in each beam to limit the radiation to a narrow spectral range. The radiations were converted into electrical signals using two identical high-speed photomultipliers (Hamamatsu, H10721-20) equipped with external amplifiers (Hamamatsu, C5594-44). The signals were digitized and recorded by a 2 $\mathrm{GHz}$ digital storage oscilloscope (Lecroy, Wavejet 354A). For particle size evaluation, the measured LII signal was fitted by calculated curves obtained by variation of count median diameter (CMD) and standard deviation $\sigma_{g}$. A least-squares method by Levenberg and Marquardt was used for curve fitting [66].

For comparison purposes, physical samples of the floating particles were collected at the outlet of each open-ended tube. Sampling was conducted by introducing copper grids at the positions where the LII signals were recorded. The copper grids were withdrawn after being exposed to the gas outlet for five seconds and used for TEM observation. TEM was performed using a FEI Titan instrument equipped with a probe-corrected condenser operating at $200 \mathrm{kV}$. The histogram of NP distribution was determined by counting and sizing the primary particles from several TEM images. The histogram was fitted by a lognormal size distribution using a least-squares method and CMD and standard deviation can be obtained. In each experimental condition, more than 100 particles were used for a statistic analysis.

\section{Results and Discussions}

The measurements were based on the model described by Eremin et al $[67,48,49]$. The detail description of the model and the procedure of determination of key parameters are demonstrated in the supplementary file. After determination of the key parameter of the LII model, the measured LII signals can be evaluated by fitting cooling curves to the experimental profiles under variation of the particle size.The representing LII signal and the best fit curve of calculated LII signal are presented in Figure 2. It was found that the LII result is in good agreement 

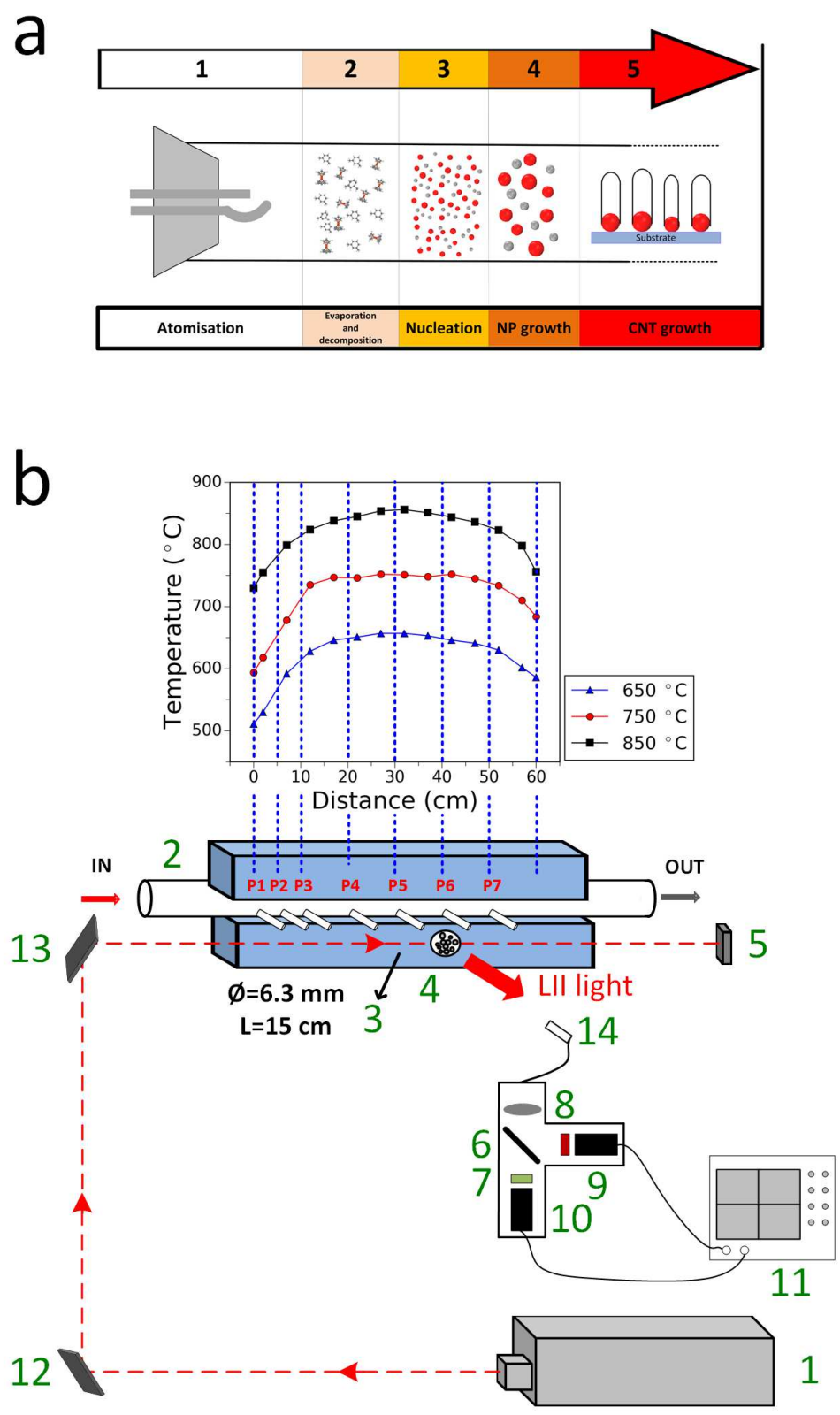

Fig. 1 (a) Schematic illustration of CNT synthesis in a FCCVD reactor. (b) Experimental setup for LII measurements. 1. Nd:YAG pulsed laser $(10 \mathrm{~Hz}, 1064 \mathrm{~nm})$. 2. The stainless steel CVD reactor. 3. Small open-ended tubes installed at different positions along the reactor (P1-P7). 4. Area containing NPs (outlet of the small tube). 5. Laser energy meter. 6. 550 nm Dichroic shortpass filter. $(7,8)$. Bandpass filter 492 and $694 \mathrm{~nm} .(9,10)$ Two PMTs. 11. Oscilloscope. $(12,13)$. Reflection mirror. 14. Optic fiber. 
with TEM measurements. As discussed in recent works [40,42, 48,49,68], variations in the assumed properties and the experimental conditions can cause errors of the evaluated particle sizes. Therefore, the sensitivity and uncertainty of the key parameters on the evaluated particle size for our LII model was estimated. In the present study, seven key parameters, NP density $\rho_{p}$, NP heat capacity $c_{p}$, thermal accommodation coefficient (TAC) $\alpha_{T}$, the ratio of the heat capacities of the gas $\gamma$, the molecular weight of ambient gas $\mu_{g}$, the gas temperature $T_{g}$ and the heat-up temperature $T_{0}^{p}$ were taking into account. The values of $\alpha_{T}$, NP density $\rho_{p}$ and NP heat capacity $c_{p}$ may be changed depending on the carbon shell structure. The uncertainty of the NP density $\rho_{p}$ depends on the $\mathrm{Fe} / \mathrm{C}$ mass ratio in particles. According to the TEM results, in the case of $\mathrm{Fe} / \mathrm{C}$ mass ratio 1:1, the uncertainty of the NP density is between $-38 \%$ and $5 \%$. While, in the case of $\mathrm{Fe} / \mathrm{C}$ mass ratio $5: 1$, the uncertainty of NP density is ranging from $-13 \%$ to $5 \%$. The carbon shell structure has a more profound influence on the NP heat capacity. For a NP with a $\mathrm{Fe} / \mathrm{C}$ mass ratio $1: 1$, the maximum possible uncertainty of the NP heat capacity reaches $+119 \%$, which is the difference between the pure iron heat capacity value and the value for $\mathrm{Fe} / \mathrm{C}$ mass ratio $1: 1$. It should be noted that only when all the NPs exhibit a core-shell structure with a $\mathrm{Fe} / \mathrm{C}$ mass ratio $1: 1$, the maximum uncertainty of the NP heat capacity can reach. But according to TEM observations, the $\mathrm{Fe} / \mathrm{c}$ mass ratio should be between 1:1 and 1:0. So the uncertainty of the NP heat capacity always is smaller than $+119 \%$ The value of $\alpha_{T}$ is determined by comparing the LII measurements with TEM results, hence the real uncertainty of $\alpha_{T}$ can not be estimated. Since the differences of normalized $\chi^{2}$ for $\alpha_{T}$ from 0.07 to 0.17 are very small during the two-parameter data-fit procedure (Figure S3b), the possible value of $\alpha_{T}$ is from 0.07 to 0.17 . The molecular weight of ambient gas $\mu_{g}$ and the ratio of the heat capacities of the gas $\gamma$ are related to the gas composition. The gas composition will change according to the CVD conditions. $\mu_{g}$ can be in the range of 28.74 (for air) to 39.39 (for argon). While, $\gamma$ is ranging from 1.39 (for air) to 1.667 (for argon). The deviation of the gas temperature $T_{g}$ and the heat-up temperature $T_{0}^{p}$ are set to be $\pm 5 \%$.

In the present study Sobol's method was used to perform a detailed sensitivity analysis for our LII model by considering each parameter's individual contribution (the first-order index $S_{i}$ ) and the total contribution (the total-order index $S_{T i}$ ) [69-72]. The greater the sensitivity indices are, the more critical parameters are for the model. An input factor will be considered to be important if it explains more than $1 / k$ ( $k$ is the number of the estimated parameter) of the output variance. For a given factor, a notable difference between $S_{T i}$ and $S_{i}$ flags an important role of interactions for that factor in the output. A detailed sensitivity analysis of these influences $\left(\rho_{p}, c_{p}, \alpha_{T}, \gamma, \mu_{g}, T_{g}, T_{0}^{p}\right)$ on the evaluated particle size for our model is presented in Figure 3a,b. Results show that the relative sensitivity is related to the $\mathrm{Fe} / \mathrm{C}$ mass ratio in the NPs. In the case of NPs with $\mathrm{Fe} / \mathrm{C}$ mass ratio $1: 1, c_{p}$ is the most important parameter. It explains $45.3 \%$ of the output variance. Followed by $\alpha_{T}$ and $\rho_{p}$, the total-order index of $\alpha_{T}$ and $\rho_{p}$ are 0.338 and 0.182 , both larger than $1 / k=0.143$. Thus $\alpha_{T}$ and $\rho_{p}$ are also important variables. Furthermore, all the input factors explain $97.8 \%$ of the output variance singly. The small difference between the total-order index and the first order index of each parameters stands for the weak interactions between the parameters, which proves their independence. For NPs with a Fe/C mass ratio 5:1, the Sobol sensitivity index of $\rho_{p}$ and $c_{p}$ are 0.04 and 0.173 , respectively. It indicates that $\rho_{p}$ and $c_{p}$ become 


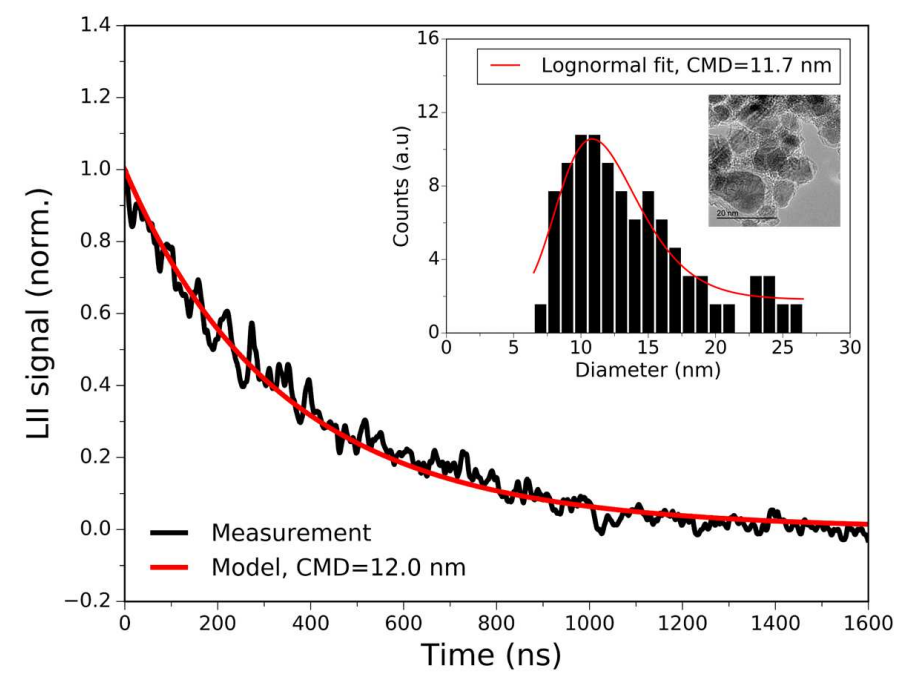

Fig. 2 Measured LII signal of NPs at the center of the reactor P5 at $850{ }^{\circ} \mathrm{C}$ in the gas phase and the best fit curve of the calculated LII signal.

less important with the increase in the $\mathrm{Fe} / \mathrm{C}$ mass ratio. More attention should be paid to the parameter $\alpha_{T}$ in the experimental application since it becomes the most important parameter, accounting for $85.6 \%$ of the variance of the response variable. The sum of the first-order index reaches 0.93 , which means that the variance of the response variable can be well explained by the uncertainty from the individual parameters.

The uncertainty of the particle size resulted from the deviation of the key parameters is also presented in Figure 3c,d. We can clearly see that the uncertainty of the particle size caused by the $\rho_{p}$ and $c_{p}$ strongly depends on the $\mathrm{Fe} / \mathrm{C}$ mass ratio of NPS. The possible deviation of the particle size for a NP with a $\mathrm{Fe} / \mathrm{C}$ mass ratio $1: 1$ caused by the $\rho_{p}$ and $c_{p}$ are $61.1 \%$ and $-54.4 \%$. But for a NP with a Fe/C mass ratio 5:1, the uncertainty of the particle size caused by $\rho_{p}$ and $c_{p}$ decrease to $-28.4 \%$ and $14.4 \%$. Furthermore, among all the parameters, $\rho_{p}, c_{p}, \alpha_{T}, \gamma$ exhibit a strong influence on the calculated particle diameter. The maximum deviation reaches $67 \%$ when $\alpha_{T}=0.17$ was chosen in the present model. While the $T_{0}^{p}$ has a very week influence on the evaluated particle diameter. $\pm 5 \%$ deviation in the $T_{0}^{p}$ only cause $0.39 \%$ and $-0.14 \%$ uncertainty on the resulted particle diameter.

The mean size evolution of NPs in the gas phase as a function of the CVD duration was investigated by LII measurements at temperature 650,750 and 850 ${ }^{\circ} \mathrm{C}$. It is found that temperature exhibits a pronounced effect on NP formation in the gas phase. No LII signals were detected at $650{ }^{\circ} \mathrm{C}$ at all positions along the reactor. LII signals were detected successfully at 750 and $850{ }^{\circ} \mathrm{C}$. Figure 4 shows the mean size evolution of NPs in the gas phase at the center of the reactor as a function of the CVD duration. The CMD of NPs are almost constant in all 60 min at both 750 and $850{ }^{\circ} \mathrm{C}$. It means that the system reaches an equilibrium state during the FCCVD process with the continuous injection of ferrocene and carbon sources. Furthermore, the evaluated $C M D$ of NPs in the gas phase by LII 
a

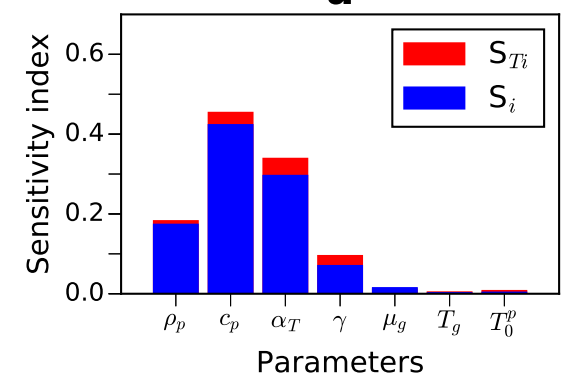

C

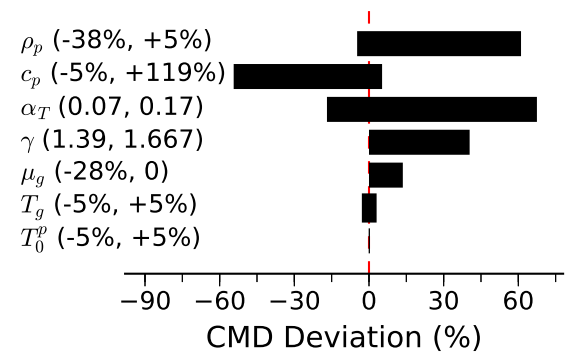

b

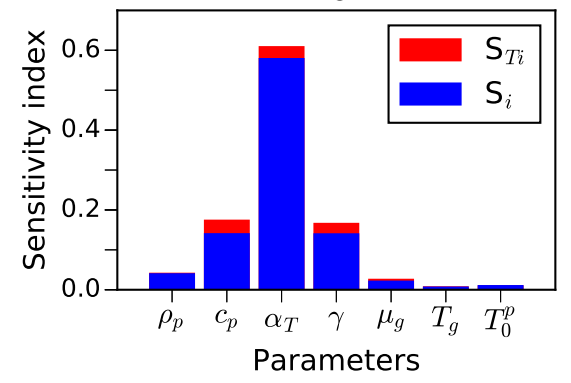

d

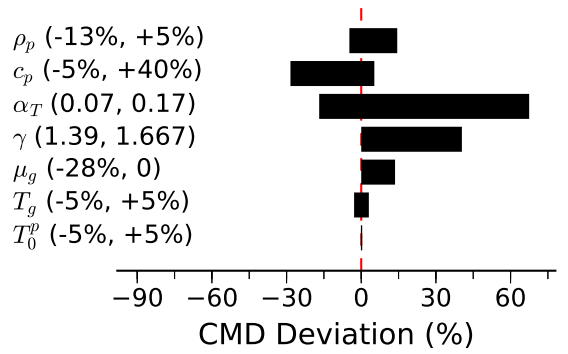

Fig. 3 The first-order $S_{i}$ and the total-order $S_{T i}$ Sobol sensitivity index of the main parameters in the LII model at the Fe/C mass ratio (a) 1:1 and (b) 5:1. Uncertainties in particle sizing by LII at the $\mathrm{Fe} / \mathrm{C}$ mass ratio (c) 1:1 and (d) 5:1.

at 750 and $850{ }^{\circ} \mathrm{C}$ are about 5.1 and $12.5 \mathrm{~nm}$ in all the time, respectively. The corresponding TEM image and size distribution of NPs obtained at 750 and 850 ${ }^{\circ} \mathrm{C}$ with CVD duration of 12 min are depicted in Figure $\mathrm{S} 6$ and in Figure 2. It can be seen that the NP size are about 5.9 and $11.7 \mathrm{~nm}$ by TEM measurements. These results suggest that the evaluated $C M D$ by LII is in good agreement with the one by TEM measurements and the $C M D$ of NPs greatly increases with the temperature increasing from 750 to $850{ }^{\circ} \mathrm{C}$.

The NP size at different position along the reactor axis at $850{ }^{\circ} \mathrm{C}$ was also evaluated by LII measurements. At P1 no LII signals were detected. At P2 very week LII signals can be detected. But the detected LII signals are too week to be analyzed for particle sizing, indicating that very few NP nucleation takes place in the gas phase at P2. From P3 to P7 we can detect strong LII signal. Therefore, the NP size from P3 to P7 can be evaluated, which is presented in Figure 5. The corresponding TEM images and size distribution of NPs are also presented in Figure S7 and Figure S8. The NP size at position P3, P4, P5, P6 and P7 obtained by LII sizing are 10.7, 10.3, 12.5, 12.2 and $11.0 \mathrm{~nm}$, respectively. In previous works computational fluid dynamics (CFD) simulations were implemented to describe NP nucleation process [73-75]. These simulations predicted that iron NP size will increase along the reactor axis. However, in the present study the evaluated NP size does not show obvious difference from P3 to P7. The NP size almost keep constant the along the reactor. Furthermore, it is well known that highly dense 
CNTs can synthesis successfully at the $650{ }^{\circ} \mathrm{C}$ on the substrate at the same CVD conditions $[76,61]$, but at $650{ }^{\circ} \mathrm{C}$ no NPs were detected in the gas phase. It is emphasized that no CNTs were found in CVD samples in the gas phase by TEM analysis (Figure S1) and the CVD samples were identified to be carbon encapsulated iron NPs. Their size is far from that on the substrate as observed in our previous study [61]. Because of the graphite layer, the carbon-encapsulated iron NPs are thermally stable, they cannot directly contribute to the CNT growth in the gas phase or coalesce on the substrate to form large NPs for the CNT growth on the substrate. Based on above discussions, it can be deduced that iron NPs on the substrate must nucleate by another mechanism. It is hypothesized that iron NPs form in the gas phase by homogeneous nucleation when the iron partial pressure is higher than its saturated vapor pressure. Since the direct bond cleavage pyrolysis of hydrocarbon carbon only happen at temperature much higher than $850{ }^{\circ} \mathrm{C}$ [49], it can be concluded that carbon atoms mainly come from the catalytic decomposition of hydrocarbon on the iron NP surface. They dissolve into iron NPs and then precipitate from iron NP surface. Once carbon atoms aggregate to a certain amount, the growth of iron NP will terminate due to the encapsulation of the carbon layers. At high temperature, fast decomposition of ferrocene will promote the NP nucleation and coalescence, finally leading to larger NPs. In addition, NPs in the gas phase are finally encapsulated by graphite layers, they do not contribute to CNT growth on the substrate. By contrast, NPs on the substrate form by heterogeneous nucleation. The substrate plays a key role in promoting the NP nucleation, which results in much larger iron NP than those in the gas phase. Thus NPs formed on the substrate can be used as the catalysts for the CNT growth in the studied conditions.

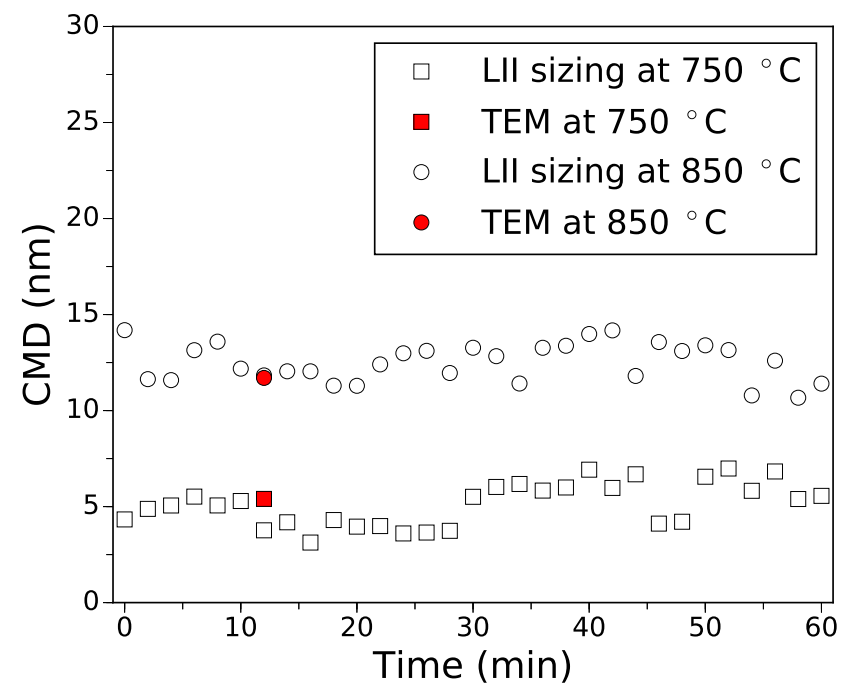

Fig. 4 NP size evolution in the gas phase at the center of the reactor as a function of CVD duration. 


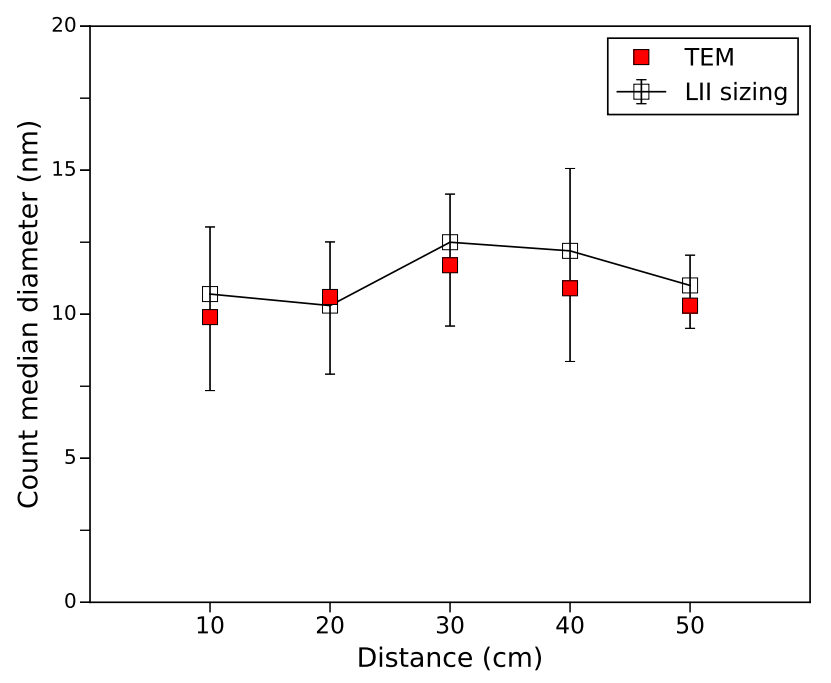

Fig. 5 NP size evolution in the gas phase at different positions in the CVD reactor at $850{ }^{\circ} \mathrm{C}$.

\section{Conclusion}

In summary, LII diagnostic technique was applied for NP sizing during the CVD synthesis of CNTs in this study. TEM shows that NPs in the gas phase exhibit a core-shell structure with an iron core and carbon shell. Therefore, the procedure of calculating the theoretical LII signal was developed for the carbon-encapsulated iron NP. A detailed sensitivity and uncertainty of the key parameters on the evaluated particle size for this model were estimated. Results show a strong dependence of the sensitivity and uncertainty on the structure of NPs. In the case of NPs with $\mathrm{Fe} / \mathrm{C}$ mass ratio 1:1, according to Sobol sensitivity index, $c_{p}, \alpha_{T}$ and $\rho_{p}$ are important parameters. The possible deviation caused by the $\rho_{p}$ and $c_{p}$ are $61.1 \%$ and $-54.4 \%$. While for NPs with $\mathrm{Fe} / \mathrm{C}$ mass ratio, $c_{p}$ and $\rho_{p}$ become less important. $\alpha_{T}$ is the most important parameter. The uncertainty of the particle size resulted from $\rho_{p}$ and $c_{p}$ also decrease to $-28.4 \%$ and $14.4 \%$. Using the developed approach, the evolution of NPs in the gas phase along the reactor axis was investigated at 650,750 and $850{ }^{\circ} \mathrm{C}$. The evaluated size by LII is in good agreement with the one obtained by TEM measurements. The NP size is highly dependent on the temperature in the studied conditions but it does not show obvious difference along the reactor axis. According to these results and discussions, it is reasonable to believe that NPs form in the gas phase by homogeneous nucleation, and they do not directly contribute to CNT growth taking place on the substrate surface.

This study demonstrates that the LII technique is a useful tool to trace the NP evolution during the floating CVD process. However, LII is limited to the detection of NPS with the size larger than serval $\mathrm{nm}$. The whole NP nucleation concerns some fundamental processes, such as decomposition of ferrocene and atoms collision. Thus in order to investigate the early stage of NP nucleation, other diagnostic techniques, such as LIF [59,77-79] or Raman, are also highly 
desired. The presence of iron atoms and carbon radicals in the gas phase would confirm the NP nucleation mechanism. Furthermore, particle agglomerates are observed in the TEM images. So a planar LII approach is expected to be applied with further modification of the furnace, to achieve a more precise visualization of the NPs coagulation regions [80].

Acknowledgements This work was carried out within the MATMECA consortium and supported by the ANR under contract number ANR-10-EQPX-37. Y. Xu gratefully acknowledges the financial support of China Scholarship Council (CSC). The authors thank Mr. Xiangtuo Chen for the helpful discussion.

\section{References}

1. A.B. Dichiara, J. Yuan, S. Yao, A. Sylvestre, L. Zimmer, J. Bai, J. Mater. Chem. A 2(21), $7980(2014)$

2. Q. Zhang, J.Q. Huang, W.Z. Qian, Y.Y. Zhang, F. Wei, Small 9(8), 1237 (2013)

3. A.B. Dichiara, S.F. Harlander, R.E. Rogers, Rsc Advances 5(76), 61508 (2015)

4. Ihsanullah, A. Abbas, A.M. Al-Amer, T. Laoui, M.J. Al-Marri, M.S. Nasser, M. Khraisheh, M.A. Atieh, Separation and Purification Technology 157, 141 (2016)

5. W. Li, A. Dichiara, J. Bai, Composites Science and Technology 74, 221 (2013)

6. G. Mittal, V. Dhand, K.Y. Rhee, S.J. Park, W.R. Lee, Journal of Industrial and Engineering Chemistry 21, 11 (2015)

7. V. Jourdain, C. Bichara, Carbon 58, 2 (2013)

8. R. Guzmán de Villoria, A.J. Hart, B.L. Wardle, ACS nano 5(6), 4850 (2011)

9. T. Yamada, A. Maigne, M. Yudasaka, K. Mizuno, D.N. Futaba, M. Yumura, S. Iijima, K. Hata, Nano letters 8(12), 4288 (2008)

10. A. Moisala, A.G. Nasibulin, E.I. Kauppinen, Journal of Physics: condensed matter 15(42), S3011 (2003)

11. C. Castro, M. Pinault, S. Coste-Leconte, D. Porterat, N. Bendiab, C. Reynaud, M. MayneL'Hermite, Carbon 48(13), 3807 (2010)

12. Q. Zhang, J.Q. Huang, M.Q. Zhao, W.Z. Qian, F. Wei, Applied Physics A: Materials Science \& Processing 94(4), 853 (2009)

13. C. Castro, M. Pinault, D. Porterat, C. Reynaud, M. Mayne-L?Hermite, Carbon 61, 585 (2013)

14. C.L. Cheung, A. Kurtz, H. Park, C.M. Lieber, The Journal of Physical Chemistry B 106(10), $2429(2002)$

15. R. Rao, D. Liptak, T. Cherukuri, B.I. Yakobson, B. Maruyama, Nature materials 11(3), $213(2012)$

16. Y. Liu, A. Dobrinsky, B.I. Yakobson, Physical review letters 105(23), 235502 (2010)

17. R.L.V. Wal, D.L. Dietrich, Appl. Opt. 34(6), 1103 (1995)

18. R.W. Weeks, W.W. Duley, Journal of Applied Physics 45(10), 4661 (1974)

19. A.C. Eckbreth, Journal of Applied Physics 48(11), 4473 (1977)

20. L.A. Melton, Applied optics 23(13), 2201 (1984)

21. P. Roth, A. Filippov, Journal of aerosol science 27(1), 95 (1996)

22. A. Filippov, M. Markus, P. Roth, Journal of Aerosol Science 30(1), 71 (1999)

23. S. Will, S. Schraml, A. Leipertz, Optics letters 20(22), 2342 (1995)

24. R.L. Vander Wal, M.Y. Choi, Carbon 37(2), 231 (1999)

25. B. Axelsson, R. Collin, P.E. Bengtsson, Applied Optics 39(21), 3683 (2000)

26. H. Bladh, P.E. Bengtsson, Applied physics b 78(2), 241 (2004)

27. D. Snelling, K. Thomson, F. Liu, G. Smallwood, Applied Physics B 96(4), 657 (2009)

28. H.A. Michelsen, P.O. Witze, D. Kayes, S. Hochgreb, Applied optics 42(27), 5577 (2003)

29. H.A. Michelsen, The Journal of chemical physics 118(15), 7012 (2003)

30. S. Dankers, A. Leipertz, S. Will, J. Arndt, K. Vogel, S. Schraml, A. Hemm, Chemical engineering \& technology 26(9), 966 (2003)

31. R.L. Vander Wal, G.M. Berger, T.M. Ticich, P.D. Patel, Applied optics 41(27), 5678 (2002)

32. D.R. Snelling, G.J. Smallwood, F. Liu, Ö.L. Gülder, W.D. Bachalo, Applied optics 44(31), 6773 (2005) 
33. B.F. Kock, B. Tribalet, C. Schulz, P. Roth, Combustion and Flame 147(1-2), 79 (2006)

34. A. Leipertz, S. Dankers, Particle \& Particle Systems Characterization 20(2), 81 (2003)

35. Y. Murakami, T. Sugatani, Y. Nosaka, The Journal of Physical Chemistry A 109(40), 8994 (2005)

36. T. Sipkens, G. Joshi, K. Daun, Y. Murakami, Journal of Heat Transfer 135(5), 052401 (2013)

37. A. Eremin, E. Gurentsov, Applied Physics A 119(2), 615 (2015)

38. L. Landström, P. Heszler, The Journal of Physical Chemistry B 108(20), 6216 (2004)

39. R.L. Vander Wal, T.M. Ticich, J.R. West, Applied optics 38(27), 5867 (1999)

40. R. Starke, B. Kock, P. Roth, Shock waves 12(5), 351 (2003)

41. A. Eremin, E. Gurentsov, C. Schulz, Journal of Physics D: Applied Physics 41(5), 055203 (2008)

42. A. Eremin, E. Gurentsov, E. Popova, K. Priemchenko, Applied Physics B 104(2), 285 (2011)

43. B.F. Kock, C. Kayan, J. Knipping, H.R. Orthner, P. Roth, Proceedings of the Combustion Institute 30(1), 1689 (2005)

44. A. Eremin, E. Gurentsov, E. Mikheyeva, K. Priemchenko, Applied Physics B 112(3), 421 (2013)

45. T. Sipkens, N. Singh, K. Daun, N. Bizmark, M. Ioannidis, Applied Physics B 119(4), 561 (2015)

46. L. Landström, K. Elihn, M. Boman, C. Granqvist, P. Heszler, Applied Physics A 81(4), $827(2005)$

47. J. Knipping, H. Wiggers, B. Kock, T. Hülser, B. Rellinghaus, P. Roth, Nanotechnology 15(11), 1665 (2004)

48. A.V. Eremin, E.V. Gurentsov, S.A. Musikhin, Materials Research Express 3(10), 105041 (2016)

49. A. Eremin, E. Gurentsov, S. Musikhin, Journal of Alloys and Compounds 727, 711 (2017)

50. E. Cenker, G. Bruneaux, L. Pickett, C. Schulz, SAE International Journal of Engines 6(1), $352(2013)$

51. R. Ryser, T. Gerber, T. Dreier, Combustion and Flame 156(1), 120 (2009)

52. B. Bougie, M. Tulej, T. Dreier, N. Dam, J. Ter Meulen, T. Gerber, Applied Physics B $\mathbf{8 0}(8), 1039$ (2005)

53. H. Oltmann, J. Reimann, S. Will, Combustion and Flame 157(3), 516 (2010)

54. T.D. Durbin, K. Johnson, D.R. Cocker, J.W. Miller, H. Maldonado, A. Shah, C. Ensfield, C. Weaver, M. Akard, N. Harvey, et al., Environmental science \& technology 41(17), 6199 (2007)

55. G.J. Smallwood, D. Clavel, D. Gareau, R.A. Sawchuk, D.R. Snelling, P.O. Witze, B. Axelsson, W.D. Bachalo, Ö.L. Gülder, SAE Transactions pp. 1345-1360 (2002)

56. M. Johnson, M. Hilton, D. Waterman, J. Black, Measurement Science and Technology 14(7), 1146 (2003)

57. P.O. Witze, SAE Transactions pp. 661-672 (2002)

58. J.D. Black, M. Hilton, M.P. Johnson, D. Waterman, in Laser Applications in Medicine, Biology, and Environmental Science, vol. 5149 (International Society for Optics and Photonics, 2003), vol. 5149, pp. 265-273

59. M. Cau, N. Dorval, B. Attal-Trétout, J.L. Cochon, A. Foutel-Richard, A. Loiseau, V. Krüger, M. Tsurikov, C.D. Scott, Phys. Rev. B 81, 165416 (2010)

60. S. Yatom, J. Bak, A. Khrabryi, Y. Raitses, Carbon 117, 154 (2017)

61. Y. Xu, Y. Ma, Y. Liu, S. Feng, D. He, P. Haghi-Ashtiani, A. Dichiara, L. Zimmer, J. Bai, The Journal of Physical Chemistry C 122(11), 6437 (2018)

62. B. Satishkumar, A. Govindaraj, R. Sen, C. Rao, Chemical Physics Letters 293(1), 47 (1998)

63. R. Xiang, E. Einarsson, J. Okawa, Y. Miyauchi, S. Maruyama, The Journal of Physical Chemistry C 113(18), 7511 (2009)

64. D. He, M. Bozlar, M. Genestoux, J. Bai, Carbon 48(4), 1159 (2010)

65. A. Dichiara, J. Bai, Diamond and Related Materials 29, 52 (2012)

66. D.W. Marquardt, Journal of the society for Industrial and Applied Mathematics 11(2), 431 (1963)

67. E.V. Gurentsov, A.V. Eremin, High Temperature 49(5), 667 (2011)

68. E. Gurentsov, A. Eremin, P. Roth, R. Starke, Kinetics and catalysis 46(3), 309 (2005)

69. I.M. Sobol, Mathematical modelling and computational experiments 1(4), 407 (1993)

70. I.M. Sobol, Mathematics and computers in simulation 55(1-3), 271 (2001) 
71. J. Nossent, P. Elsen, W. Bauwens, Environmental Modelling \& Software 26(12), 1515 (2011)

72. G. Glen, K. Isaacs, Environmental Modelling \& Software 37, 157 (2012)

73. K. Kuwana, K. Saito, Proceedings of the combustion institute 31(2), 1857 (2007)

74. D. Conroy, A. Moisala, S. Cardoso, A. Windle, J. Davidson, Chemical Engineering Science 65(10), 2965 (2010)

75. S. Futko, B. Shulitskii, V. Labunov, E. Ermolaeva, Journal of Engineering Physics and Thermophysics 88(6), 1432 (2015)

76. Y. Ma, A.B. Dichiara, D. He, L. Zimmer, J. Bai, Carbon 107, 171 (2016)

77. P. Ho, M.E. Coltrin, W.G. Breiland, The Journal of Physical Chemistry 98(40), 10138 (1994)

78. Y. Nozaki, K. Kongo, T. Miyazaki, M. Kitazoe, K. Horii, H. Umemoto, A. Masuda, H. Matsumura, Journal of Applied Physics 88(9), 5437 (2000)

79. C. Kaminski, P. Ewart, Applied Physics B 61(6), 585 (1995)

80. S. Yatom, A. Khrabry, J. Mitrani, A. Khodak, I. Kaganovich, V. Vekselman, B. Stratton, Y. Raitses, MRS Communications 8(3), 842 (2018) 